\title{
Research Progress of the Salt Barrier in Saline Alkali Land
}

\author{
Xiaomei Sun ${ }^{1,2,3,4}$, Jian Wang ${ }^{1,2,3,4}$, Dongwen Hua ${ }^{1,2,3,4, *}$ \\ ${ }^{1}$ Key Laboratory of Degraded and Unused Land Consolidation Engineering, the Ministry of Natural Resources of China, Xi'an 710075 \\ China \\ ${ }^{2}$ Shaanxi Provincial Land Engineering Construction Group, Xi'an 710075, China \\ ${ }^{3}$ Insititute of Land Engineering and Technology, Shaanxi Provincial Land Engineering Construction Group, Xi'an 710075, China \\ ${ }^{4}$ Shaanxi Provincial Land Consolidation Engineering Technology Research Center, Xi'an 710075, China
}

\begin{abstract}
As an important land resource, the poor physical and chemical properties of soil in saline alkali land are the biggest obstacle to plant growth and development in saline alkali land. Carrying out targeted research on saline alkali land improvement is of great significance to ensure food security and protect the ecological environment. In recent years, it is urgent to fully tap the potential of such areas in agricultural production and ecological greening through economic and effective original soil improvement measures. The existing research and engineering projects of saline alkali land treatment at home and abroad are mostly realized through water conservancy, physics, chemistry, biology and other measures, and tend to form a comprehensive treatment system integrating engineering, plant, microorganism and other technologies. Among them, salt separation layer + concealed pipe drainage is a more effective and commonly used engineering measure in saline alkali land treatment. Through the research and development of supporting new materials and processes, constantly improving the technical system can greatly promote saline alkali land treatment. This paper discusses the improvement of salt barrier in saline alkali soil
\end{abstract}

Key words: Salt barrier; Saline alkali land; Biochar.

\section{Introduction}

Soil salinization is a serious problem facing agriculture in the world [1-4]. The accumulation of salt in soil and groundwater threatens agricultural production and its sustainable development [5-6]. The increase of soil salt content and salinization area lead to the salinization of fertile land, the sharp decrease of crop yield, the change of land planting adaptability, and even fallow and fallow in the region [7-9].

The core problem of saline alkali land treatment is the problem of water. Less water is early and more waterlogging is more. The level of saline alkali and groundwater level is directly related to climate change. The key to comprehensive treatment is to control water. Without water control, it is impossible to improve soil. However, we can't just drain water, and drainage will also bring a series of problems. Therefore, we must change the water and soil distribution, then change the regional salt distribution, reduce human intervention, and emphasize dynamic adaptive adjustment and balance. The law of soil water and salt movement is to study the characteristics and change law of water and soil soluble salt in different periods with environmental conditions in a certain ecological environment. Soil texture, structure, fertility, salt content of soil and groundwater, high and low water level all have a great impact on water and salt movement.
In addition, climate and vegetation all have an impact on water and salt movement. Correctly understanding the law and relationship of water and salt movement is the key to regulating soil salinity and alkalinity.

In recent years, it is urgent to fully tap the potential of such areas in agricultural production and ecological greening through economic and effective original soil improvement measures. The existing research and engineering projects of saline alkali land treatment at home and abroad are mostly realized through water conservancy, physics, chemistry, biology and other measures, and tend to form a comprehensive treatment system integrating engineering, plant, microorganism and other technologies. Among them, salt separation layer + concealed pipe drainage is a more effective and commonly used engineering measure in saline alkali land treatment. Through the research and development of supporting new materials and processes, constantly improving the technical system can greatly promote saline alkali land treatment.

\footnotetext{
Corresponding author: 739972229@qq.com
} 


\section{Research status}

In nature, due to the effects of meteorological, hydrological, geological and biological processes, soil is not a simple homogeneous material, but mostly presents a staggered layered structure. Miller and Gardner (1962) [10], in 1962, conducted infiltration tests of sand covered and sand covered layered soil respectively, which proved that when the texture and hydraulic conductivity of the subsoil are different from that of the topsoil, its role will be to reduce the infiltration rate, regardless of whether the subsoil is coarser or finer than the topsoil. And although the infiltration on the surface did not stop, the wetting front stopped moving forward for a period of time. Hill and parlange (1972) [11] found that when the wetting front passes through the fine and coarse sand interface, the wetting front becomes "fingers flow", and the water is retained at the fine and coarse sand interface. Hillel and Baker (1988) [12] analyzed the formation mechanism of "finger flow" phenomenon from the viewpoint of energy conservation, and believed that soil stratification would lead to the instability of wetting front, that is, in the early stage of ponding infiltration, the wetting front was located in the upper fine soil with low hydraulic conductivity, and the soil suction at the wetting front was large, so that the water can not directly enter the coarse sand layer with high hydraulic conductivity after reaching the interface, the wetting front pauses at the interface, while the upper water continues to infiltrate under the water potential gradient, and the water suction gradually decreases until the water can enter the smallest pore connected with the lower layer, and then reduce to the surrounding macropores.

The groundwater level in saline alkali areas is generally high and contains a certain amount of salt. Therefore, the rising height of capillary water and water conveyance speed have a great impact on soil salt accumulation. WillisW. O. (1960) [13] and Miller D E. (1962) [10] found in the test of layered soil that when the capillary water rises through the interface of layered soil composed of clayey sand, there is a stagnation phenomenon, and the stagnation time increases with the increase of interlayer level and the difference between soil and sand particle size. Luo Huanyan (1965) [14] of China also discussed this phenomenon. Shi Wenjuan (2004) [15] systematically demonstrated the influence of sand layer on the rise of soil capillary water through indoor test, and proposed that sand layer will affect the height and speed of capillary water rise.

The effect of soil interlayer on evaporation is mainly clay interlayer soil. There are mainly two views on the influence of clay layer on evaporation. One view is that the closer the clay layer is to the groundwater level, the more difficult it is for the surface to return salt $[16,17]$; Another view is that the inhibition of clay layer on salt is strengthened with the increase of its horizon [18-20]. Most views believe that the salt inhibition is stronger with the increase of clay interlayer thickness $[18,19,21]$. Shi Wenjuan (2004) [15] is the most systematic research on the influence of sand layer soil on soil salt accumulation during evaporation. She puts forward that the influence of sand layer on phreatic evaporation intensity, soil surface return salt and salt solution concentration is basically the same as that of sand layer on capillary water rising speed. At the same time, salt is retained at the upper and lower interfaces of soil and sand, and the higher the sand layer or the larger the effective particle size, the greater the retention. And the inhibition rate of sand layer to salt is greater than that to water. In addition, the sand layer has different effects on the movement of different ions, among which $\mathrm{Na}+$ and $\mathrm{Cl}-$ are most affected by the sand layer.

Salt barrier technology is mainly realized by the change of water and salt movement caused by the change of soil layer. According to the principle of soil water energy, when water infiltrates into layered soil, regardless of whether the texture of the interlayer soil is thicker or finer than that of the surface soil, the soil interlayer will block the water flow, increase the water storage capacity of the upper soil, and then reduce the infiltration [22]. The research on saline alkali soil barrier [23-25] shows that the soil barrier causes uneven pore distribution at the junction of soil barrier, affects the soil moisture content, hydraulic gradient and conductivity, changes the movement track of soil moisture at the junction of soil barrier, and then affects the law of soil water and salt movement in saline alkali soil and the leaching and improvement of saline alkali soil. Biochar is a solid product of organic materials after pyrolysis under high temperature and hypoxia [26], which has the characteristics of high carbon content, high porosity, strong adsorption and high stability [27]. Biochar materials have been widely and deeply studied in the fields of soil improvement, fertilization, soil pollution remediation, water pollution remediation and coping with greenhouse effect at home and abroad. Biochar materials are generally alkaline, but subject to the influence of raw materials, some are also acidic, such as the preparation of biochar from furfural residue [28]. Biochar generally contains high calcium content [29], which helps to exchange $\mathrm{Na}+$ in saline alkali soil and promote the formation of soil agglomeration structure; The porosity of biochar material is conducive to improve soil structure and form hydraulic conductivity; The low apparent density makes its transportation and construction more convenient. In addition, due to the structural stability of biochar itself, it can maintain a long-term effect. Biochar materials have certain application potential in saline alkali land improvement. The existing research on biochar in saline alkali land improvement [30] mainly adopts the mixing method, paying attention to soil physical and chemical properties, plant growth and soil respiration.

\section{Conclusion}

The research on the law of soil water and salt transport is not only an important aspect of soil physics and farmland irrigation, but also the core problem of preventing and improving saline soil. In the previous research on soil salt barrier, it is mainly Sandy and clay salt barrier. In addition, in recent years, straw has been used as a salt barrier and its water and salt movement law has been studied. In terms of construction, granular biochar is similar to the traditional gravel and stone chip salt separation layer. 
There are no obstacles in the construction technology. Due to the lightweight characteristics of its materials, its construction is more flexible and convenient. Mechanical construction can be carried out in a large range and manual construction can also be used in a small range. In terms of material cost alone, the price of biochar is higher than that of the traditional gravel salt barrier, but the preparation of biochar takes agricultural and forestry wastes as raw materials, which is an effective way for the resource utilization of agricultural and forestry wastes, and can play a huge ecological benefit in reducing carbon emissions.

The selection of salt barrier has a great impact on the effectiveness of saline alkali land treatment. In view of the problems such as easy decomposition and decay of straw, inconvenient transportation and construction of sand and gravel materials, the porous structure (enhanced drainage), light material (convenient for construction), high stability (long-term effect), strong adsorption and other properties of biochar materials can be fully utilized, This paper explores its leaching and salt suppression effect as a salt barrier of saline alkali soil, and discusses the positive role of salt barrier materials in the construction of saline alkali soil, so as to provide scientific basis and theoretical support for the improvement and restoration of saline alkali soil.

\section{Acknowledgments}

This work was financially supported by the Fund Project of Shaanxi Key Laboratory of Land Consolidation (2019JC08) and the Fund Project of Shaanxi Provincial Land Engineering Construction Group Internal Research Project (DJNY2021-25). Sincere gratitude is extended to the editor and anonymous reviewers for their professional comments and corrections.

\section{References}

1. Han Jichang. Study on comprehensive management model and mechanism of saline alkali land in halobotan, Shaanxi. Xi'an University of technology, 2009.

2. Zhang Yuwen Improvement of physical properties of coastal saline alkali cotton field by straw returning. Tai'an: Shandong Agricultural University, 2016.

3. Ye Xiaofei Study on salt transport law between water body of storage ditch and adjacent soil under water storage condition. Xi'an: Xi'an University of technology, 2010.

4. Li Bin, Wang Zhichun, sun Zhigao, et al. Study on saline alkali land resources and sustainable utilization in China. Agricultural research in arid areas, 2005,23 (2): 154-158.

5. SCHOUPS G, HOPMANS J W, YONG C A, et al. Sustainability of irrigated agriculture in the San Joaquin Valley, California. PNAS, 2005, 102(43):15352-15356 .
6. Sun Zhaojun Study on improvement model of saline alkali wasteland in Yinchuan Plain. Beijing: Beijing Forestry University, 2011.

7. R OZEMA J, FLOWE R S T . Crops for a salinized world. Science, 2008, 322 ( 5907) :1478-1480 .

8. Zhou Zaiming Study on spatial variability and influence mechanism of soil salinity in low plain around Bohai Sea.Beijing: Chinese Academy of Geological Sciences, 2012.

9. Wang Xianghui Research on environmental change and agricultural sustainable development in Northwest China. Yang Ling: Northwest University of agriculture and forestry science and technology, 2012.

10. Miller D E, Gander W H. Water infiltrate into the stratified soil. Soil Sci Soc Amer Proc, 1962,26:115118.

11. Hillel D E, Parlange J Y. Wetting front instability in layered soil. Science Society American Proceeding, 1972,36(5):697-702.

12. Hillel D, Baker $\mathrm{R} S \mathrm{~A}$. descriptive theory off fingering during infiltration into layered soils. Soil Science, 1988,146(1):51-55.

13. Willis W O. Evaporation from layered soils in the presence of a water table. Soil Sci Soc AmJ. 1960,24(4):239-242.

14. Luo Huanyan, Xie Juhua Experimental study on capillary water rise in layered soil. Journal of soil, 1965,13 (3): 312-324.

15. Shi Wenjuan, Wang Zhirong, Shen Bing, et al Experimental study on capillary water rise of soil configuration in sand intercalated layer [J] Journal of soil, 2004,18 (6): 167-170.

16. Yuan Jianfang, Zhou Yuehua Influence of clay interlayer on groundwater ascending operation. Journal of soil, 1980,17 (1): 94-99.

17. Liu Fuhan, Wang zunqin Soil water and salt movement in different soil profiles under phreatic evaporation. Journal of soil, 1993.30 (2): 173-180.

18. Liu Siyi, Liang Guoqing, Xing Wengang, et al Experimental study on water and salt movement in clay interlayer soil structure. Journal of soil, 1992, 29 (1): 109-112.

19. Liu Siyi, Wei Youqing Study on several factors affecting soil salinization in Majia River Basin. Journal of soil, 1988.25 (2): 110-118.

20. Wang Jinping Numerical simulation of layered soil water movement under evaporation. Journal of water conservancy, 1989.5:49-54.

21. Liu Youchang Discussion on critical depth of groundwater in Lubei Plain. Soil bulletin, 1962, 24:13-22.

22. Shao Ming'an, Wang Quanjiu, Huang mingbin, soil physics [M] Beijing: Higher Education Press, 2006:23-36.

23. Yin Xiaolin, Ding Guodong, Zhang Weicheng. Effects of rainfall and salt barrier on water and salt 
movement in coastal saline alkali land Chinese Journal of soil and water conservation, 2011,9 (3): $40-44$.

24. Zhang Jianfeng, Wang Wenyan, Wang Zhirong, et al. "Calculation of soil infiltration with sandy interlayer" $[\mathrm{J}]$. Journal of agricultural engineering, 2004,20 (2): 27-30.

25. Shi Wenjuan, Shen Bing, Wang Zhirong, et al Study on soil water and salt transport characteristics of shallow groundwater with sand layer under evaporation. Journal of agricultural engineering, 2005,21 (9): 23-26.

26. Bridgwater A V D. Meier D. Radlein. An overview offast pyrolysis of biomass. Organic Geochemistry1999,30:1479-1493.

27. Didem O. Aysegul E M. Characterization of biocharand bio-oil samples obtained from carbonization of various biomass materials. Renewable Energy, 2010.351319-1324.

28. Sun Junna, Dong Lukang, Xu Gang, et al Comparative study on the effects of furfural residue and its biochar on the physical and chemical properties of saline soil. Journal of Agricultural Environmental Sciences, 2014.33 (3): 532-538.

29. Gerardo O. Stefania M. Anna A. et al. Are soilwaterfunctions affected by biochar application? Geoder-ma, 2015.249/250:1-11.

30. Vijayasatya N C. David M C. Evaluating the relativecontribution of physiochemical and biological factors inameliorating a saline-sodic soil amended with composts and biochar and leached with reclaimed water. Geo-derma,2015,259/260:4555. 